\title{
The Main Characteristics of Freight on Hot Streams
}

\author{
EROFEEVA Natalya V.,CHEBOTOVA Irina N. \\ Mining Institute, Institute of Thermal Power, T.F. Gorbachov Kuzbass State \\ Technical University, 65000 Kemerovo, Russia
}

\begin{abstract}
Authors determined temperature of the extinguished coke by fractional structure. Authors suggested to lower temperature influence from the large heated pieces on a tape at the expense of loads segregation.
\end{abstract}

Keywords: conveyer belt, coke, temperature, segregation, fraction

\section{Introduction}

Belt conveyors are applied to transportation of hot freight at cokechemical plants. Theconveyer belt is the most vulnerable element. The cost of a belt makes from 40 to $70 \%$ of cost of the conveyor. The belt fails because of thermal aging and burning by the heated pieces in case of violation of a technological mode. Suppression of coke happens in two stages. One stage is that the heated coke is unloaded in the wagon where suppression by wet way is made. The other is that further coke is unloaded on a ramp where there is an extinguishing of the heated centers. Temperature of the extinguished coke is one of the main of the characteristics necessary for a right choice of conveyor transport on hot traffics of loads.

\section{Characteristic of the work}

At Cherepovets iron and steel works ${ }^{[1]}$, researches of temperature of coke of wet suppression were conducted. In work it is noted that at wet suppression of 7-10 percent of coke have temperature of 100 160 degrees, the rest - less than 100 degrees Celsius. At the same time in the lump of transported coke of wet suppression pieces (2-5\%), surfaces having temperature to $700-800$ of degrees Celsius meet. Similar results were received by authors at research of temperature of a surface of coke at the Kemerovo coke-chemical plant (fig. 1, f). Thus the maximum temperature of a surface of coke reached 550-600 of degrees Celsius.

The granulometric structure of freight has a great impact on extent of cooling. Smaller fractions making bulk of transported freight are exposed to deeper cooling. Large pieces are exposed to superficial cooling and in the course of further movement from a stage on the conveyor are warmed due to remained internal heat.

Unfortunately, in work ${ }^{[1]}$ the attention to distribution of temperature of a surface of coke on fractional structure isn't focused.

Authors tried to take on the working conveyor at a factory temperature of a surface of coke on fractional structure 0-50 mm; 50-100 mm; 100-150 mm; 150-200 $\mathrm{mm}$ and $+200 \mathrm{~mm}$ (fig .1, $a-e$ ). Measurements were made in the contactless way by a pyrometer.

The expected temperature of the coke unloaded on the belt conveyor, at confidential probability of $95 \%$ is specified in Tab. 1. 
a)

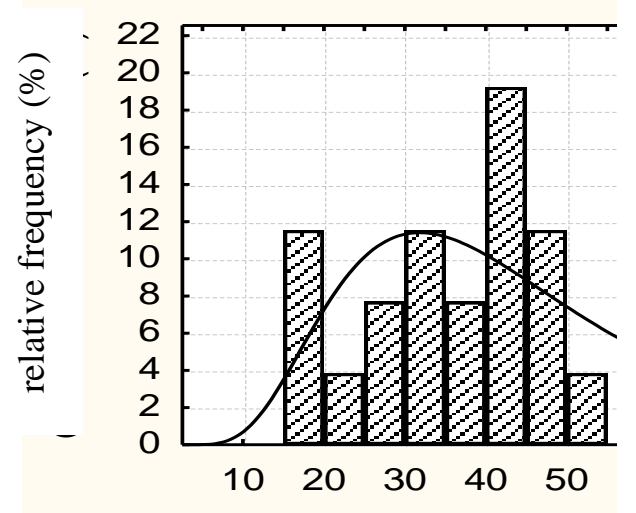

Temperature, ${ }^{\circ} \mathrm{C}$

c)

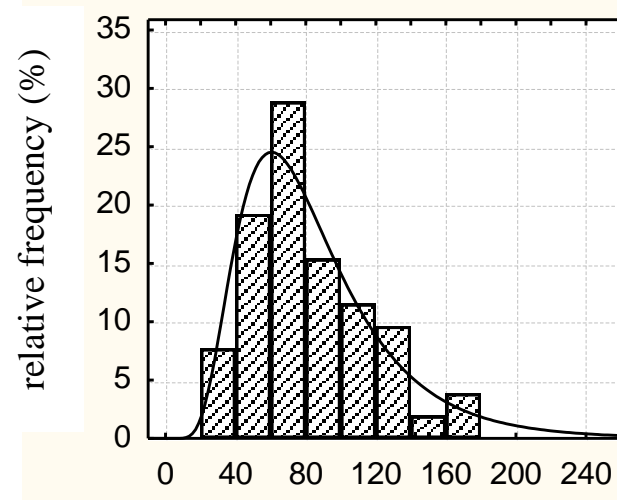

Temperature, ${ }^{\circ} \mathrm{C}$

e)

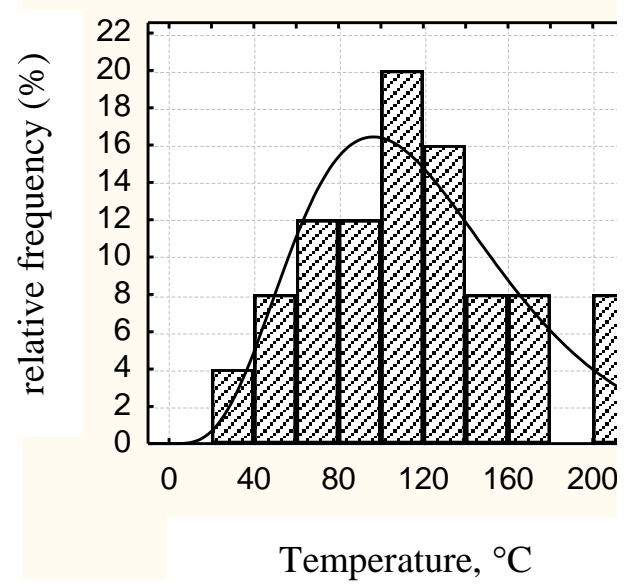

b)

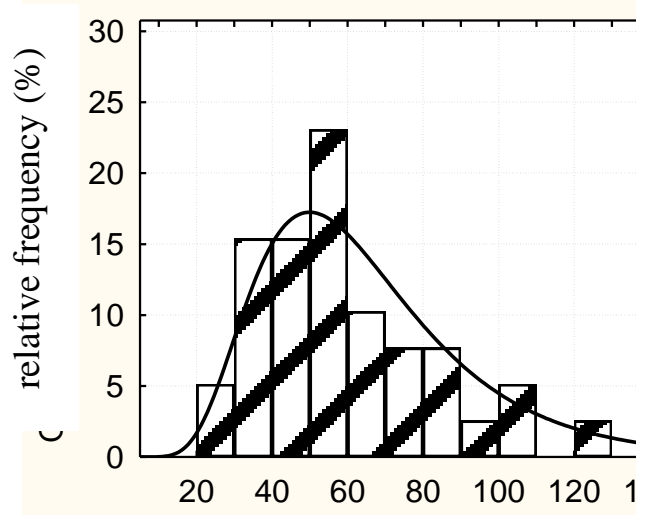

Temperature, ${ }^{\circ} \mathrm{C}$

d)

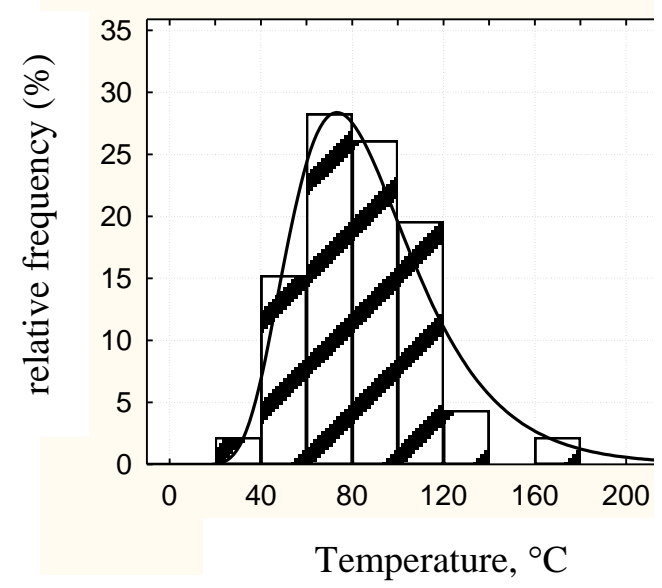

f)

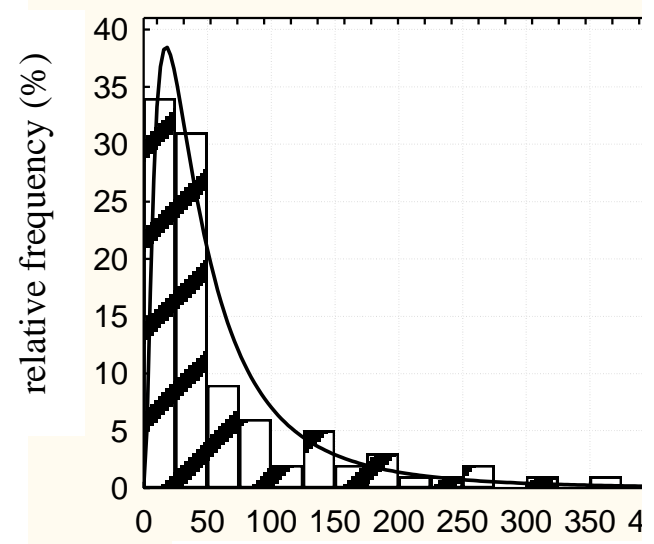

Temperature, ${ }^{\circ} \mathrm{C}$

Fig. 1: Histograms of distribution of temperature of a surface of coke of fraction: 
$a-0-50 \mathrm{~mm} ; b-50-100 \mathrm{~mm} ; c-100-150 \mathrm{~mm} ; d-150-200 \mathrm{~mm} ; e-+200 \mathrm{~mm} ; f-0-300 \mathrm{~mm}$ ( including pieces of red hot) and the distribution function: $a, b, c, d, f-\operatorname{lognormal} ; e-$ gamma

Table 1: Coke temperature on fractional structure

\begin{tabular}{|c|l|l|l|l|l|l|}
\hline Fractions, $\mathrm{mm}$ & +50 & $50-100$ & $100-150$ & $150-200$ & +200 & $0-300$ \\
\hline $\begin{array}{c}\text { Range of } \\
\text { temperature, }{ }^{\circ} \mathrm{C}\end{array}$ & $35,2-51,1$ & $55,5-75,2$ & $72,6-98,4$ & $78,6-99,2$ & $98,5-141,1$ & $53,2-90,0$ \\
\hline
\end{tabular}

Apparently from Tab. 1, the bulk of transported coke has temperature not exceeding $150^{\circ} \mathrm{C}$. But at the same time pieces of a red incandescence meet. Presence of coke of a red incandescence leads to burning of a working lining of the conveyor, and sometimes and a belt framework. In special situations, when unloading on a coke tape to the high maintenance of pieces of a red incandescence (or the centers) there can be a belt ignition ${ }^{[2]}$.

\section{Conclusion}

As the small fraction of a transported material is heated to $50^{\circ} \mathrm{C}$ and most to $140^{\circ} \mathrm{C}$, it is offered to use small fraction as a layer between larger pieces and a belt, thereby having lowered temperature load of a belt. Such distribution of freight can be received shock and vibration influence on a non-working facing of a loaded branch of the conveyor. In case of hit of the single heated piece on a belt surface the piece as a result of vibration will make micro jumps. During free flight of a piece at the expense of its flow it will start being cooled with an air stream intensively and by that reducing not only the general time of contact with a belt, but also a piece thermolysis to a belt.

\section{References}

[1] Ananyev N V., Partina T. V., Shreyder E. M., Toletova V. A. About a choice of conveyer belts for transportation of coke of wet suppression //Coke and chemistry. - 1985. - \# 2. - p. 21-23.

[2] Makhlis F. A., Chertkov O. S., Borinstein G. A., Ananyev N. V., Mikheyeva I. L., Gavrilina S. A. Heatresistant conveyer belts //Hoistingand-transport equipment and warehouses.

- 1991. - \# 4. - p. 20-23. 